\title{
A influência da arte do palhaço na formação acadêmica do profissional de saúde
}

\author{
Fabiane de Amorim Almeida ${ }^{1}$ e Caroline Ribeiro Louro ${ }^{2}$ \\ ${ }^{1}$ Faculdade Israelita de Ciências da Saúde Albert Einstein, Brasil | \\ fabi.almeida17@outlook.com | https://orcid.org/0000-0002-8062-3579 \\ 2 União das instituições de Serviço, Ensino e Pesquisa LTDA- Faculdade Peruíbe, Brasil \\ crl1990@gmail.com | http://orcid.org/0000-0001-8692-7859
}

\begin{abstract}
Resumo: Introdução: Profissionais de saúde estão em contato constante com pessoas e a maneira como se relacionam com elas delineia-se a partir da sua formação acadêmica. Um ensino fundamentado nos princípios da humanização e na empatia pode influenciar significativamente nos relacionamentos interpessoais construídos pelo graduando no futuro. Para algumas instituições de ensino, o uso da linguagem do palhaço é uma forma de proporcionar ao estudante da área da saúde o desenvolvimento de habilidades socioemocionais, muitas vezes subestimadas na educação tradicional em saúde. Objetivo: Compreender o significado da vivência dos profissionais de saúde ao participar de um projeto de extensão sobre a arte do palhaço enquanto graduando. Métodos: Estudo descritivo, de abordagem qualitativa, realizado com 19 profissionais de saúde que participaram do projeto de extensão denominado "Narizes de Plantão" durante a graduação. Os dados foram coletados por meio de entrevistas semiestruturadas gravadas em vídeo, sendo analisados a partir da Análise Qualitativa do Conteúdo, utilizando-se o Interacionismo Simbólico como referencial teórico. Resultados: Ao relatarem a vivência da arte do palhaço, os participantes expressaram o impacto positivo, transformador e auto terapêutico do projeto durante a graduação, incluindo o desenvolvimento de habilidades socioemocionais em suas vidas acadêmicas. Conclusão: A arte do palhaço mostrou-se uma poderosa ferramenta transformacional e educacional, auxiliando na formação de profissionais de saúde mais empáticos e humanizados. A investigação qualitativa, dada a sua natureza, possibilitou explorar esta realidade em suas diferentes nuances.
\end{abstract}

Palavras-chave: Educação Superior; Pessoal de Saúde; Terapia do Riso; Jogos e brinquedos; Humanização da Assistência.

\section{The influence of clown art on the academic training of health professionals}

\begin{abstract}
Introduction: Health professionals are in constant contact with people and the way they relate to them is outlined from their academic background. Teaching based on the principles of humanization and empathy can significantly influence the interpersonal relationships built by the student in the future. For some educational institutions, the use of clown language is a way to provide health students with the development of socio-emotional skills, often underestimated in traditional health education. Objective: To understand the meaning of the experience of health professionals when participating in an extension project on the art of the clown while graduating. Methods: Descriptive study, with a qualitative approach, carried out with 19 health professionals who participated in the extension project called "Nose on Duty" during graduation. The data were collected through semi-structured interviews recorded on video, being analyzed from the Qualitative Content Analysis, using Symbolic Interactionism as a theoretical framework. Results: When reporting the experience of the clown's art, the participants expressed the positive, transformative and self-therapeutic impact of the project, during graduation, including the development of socio-emotional skills in their academic lives. Conclusion: The art of the clown proved to be a powerful transformational and educational tool, helping to train more empathetic and humanized health professionals. Qualitative research, given its nature, made it possible to explore this reality in its different nuances.
\end{abstract}

Keywords: Higher Education; Health Personnel; Laughter Therapy; Play and Plaything Humanization of Assistance.

\section{Introdução}

Em diversos países do mundo, incluindo o Brasil, a linguagem do palhaço tem sido introduzida em cursos de graduação, com a finalidade de estimular o desenvolvimento de habilidades cognitivas e sociais nos futuros profissionais (Nogueira-Martins, Lima-Costa, Nogueira-Martins, \& Nogueira-Martins, 2014). 
Durante a formação acadêmica do aluno na área da saúde, o seu desenvolvimento pleno deveria ser estimulado, como forma de assegurar seu fortalecimento emocional, uma vez que é exposto a várias situações geradoras de ansiedade e medo no cotidiano de trabalho (Cardozo, \& Munari, 2005).

Projetos universitários de extensão envolvendo "palhaços hospitalares" têm se revelado uma importante estratégia pedagógica, favorecendo o desenvolvimento do pensar, do sentir e do agir, num contexto mais humanista (Nogueira-Martins, Lima-Costa, NogueiraMartins, \& Nogueira-Martins, 2014).

Professores, estudantes e profissionais da saúde que tenham a oportunidade de colocar em prática os conhecimentos obtidos por meio da vivência com a arte do palhaço, estarão colaborando consideravelmente para formação de novos modelos no ensino do cuidado humanizado (Rolim, Campos, Cardoso, \& Silva, 2004).

No Brasil, o site dos "Doutores da Alegria" apresenta 1.155 iniciativas cadastradas que utilizam a linguagem do palhaço em ambiente hospitalar, contabilizando 17.633 participantes, dentre eles, estudantes e profissionais de saúde. Esse grupo, que se caracteriza como uma organização sem fins lucrativos, faz uso da arte do palhaço para intervir junto a pessoas em situações de fragilidade e apuro social, em hospitais e outros ambientes (Doutores da alegria, 2020).

Faz-se necessário implementar modificações curriculares nos cursos de graduação da área da saúde, para que o olhar humanístico não fique apenas na teoria e consiga transcender para a prática profissional (Cardozo, \& Munari, 2005; Nunes, Silva, \& Pires, 2011)

Diante disso, este estudo busca compreender o significado da vivência dos profissionais de saúde ao participar de um projeto de extensão sobre a arte do palhaço durante o curso de graduação.

\section{Metodologia}

Estudo descritivo, qualitativo, realizado com 19 profissionais de saúde que participaram do projeto de extensão, denominado "Narizes de Plantão", como graduandos ou funcionários de uma universidade privada do estado de São Paulo, Brasil. A amostra constituiu-se dos profissionais que foram contactados, por meio do cadastro fornecido pelo coordenador do projeto, e aceitaram o convite para fazer parte do estudo. Neste projeto, os participantes entram em contato com a maneira de se comunicar do palhaço e a utilizam no hospital com o objetivo de modificar o ambiente hospitalar (Narizes de Plantão, 2019).

A idade dos participantes variou entre 23 e 54 anos (média = 29 anos), sendo a maioria do sexo feminino (15; 79\%). O tempo de participação no projeto "Narizes de Plantão" variou entre seis a 60 meses e apenas dois participantes ainda continuam vinculados ao projeto. Quanto à categoria profissional, seis eram médicos, cinco biomédicos, quatro nutricionistas, dois fisioterapeutas, um terapeuta ocupacional e um docente de enfermagem.

Para participarem da pesquisa, os profissionais deveriam ter feito pelo menos uma visita em hospital como "palhaço hospitalar" do projeto e estar atuando, no momento da coleta dos dados, como profissional da área da saúde.

Os dados foram coletados entre abril e agosto de 2019, por meio de entrevistas semiestruturadas audiovideogravadas, realizadas via online, por meio do aplicativo Google Hangouts, possibilitando sua transcrição literal. Todas as imagens foram tratadas como confidenciais e utilizadas apenas para os fins da pesquisa. Além disso, os participantes assinaram o termo de autorização da imagem antes do início da entrevista. 
Utilizou-se um roteiro contendo dados pessoais dos entrevistados e três perguntas norteadoras: "Como foi para você participar do projeto 'Narizes de Plantão' durante o curso de graduação?"; "O que motivou você a participar do projeto 'Narizes de Plantão'?"; "Conte-me uma experiência em que você utiliza na prática as técnicas apreendidas durante o projeto 'Narizes de Plantão'”.

Para análise das entrevistas, utilizou-se a Análise Qualitativa de Conteúdo e o Interacionismo Simbólico (IS), como referencial metodológico e teórico, respectivamente.

O IS tem como foco principal a natureza da interação relacionada às experiências humanas (Charon, 2004). Possui três ideias centrais: o ser humano age em relação ao mundo a partir dos significados que oferece para ele; os significados decorrem da interação social que o indivíduo mantém com as demais pessoas; e os significados surgem de um processo interpretativo, utilizado pelo indivíduo ao se relacionar com objetos ou pessoas (Blumer, 1969).

Para compreender o IS, são apresentados seus conceitos básicos:

- Símbolo: considerado um objeto social (o que vemos e interpretamos) cujo significado é definido na interação do indivíduo consigo e com os outros. Permite a comunicação, a socialização e a interpretação individual e coletiva, ressaltando que toda comunicação humana é simbólica;

- Linguagem: um tipo de símbolo cultural, social e sistematicamente estabelecido para expressar aos outros e a nós mesmos o que pensamos, observamos e imaginamos;

- Self: definido como o ambiente interno da própria pessoa, sendo que o indivíduo nasce com ele, entretanto é redefinido socialmente ao interagir com os outros, tornando-se constantemente passível de mudanças;

- Mente: ação simbólica para o self, por meio da qual o indivíduo pode manipular os símbolos e se comunicar consigo mesmo por meio dos pensamentos, por exemplo. Surge da interação com os outros;

- Assumir o papel do outro: é o conceito central do IS, pois ao assumir o papel do outro, o indivíduo pode entendê-lo e se fazer entendido por ele;

- Ação humana: fruto de decisões em relação à interpretação das situações nas quais o indivíduo se encontra, sofre influência da interação com os outros e com o self (Blumer, 1969; Charon, 2004).

Este referencial teórico possibilita ampliar a compreensão de significados e experiências referentes à interação entre indivíduos e uma situação vivenciada (Ribeiro \& Pettengill, 2006), motivo pelo qual foi adotado neste estudo, que busca apreender a experiência de interação dos profissionais de saúde com o processo de descoberta do palhaço.

Quanto à Análise Qualitativa do Conteúdo, é vastamente empregada em pesquisas na área de saúde, que buscam investigar sobre um fenômeno específico e ampliar o seu conhecimento, sem prejudicar o rigor científico. Possui três modalidades, dirigida, somatória e convencional, sendo que todas propõem-se a interpretar o conteúdo do discurso. Diferenciam-se, contudo, pela forma de organização dos esquemas de codificação dos dados e pelo tratamento das unidades de significado (Hsieh, \& Shannon, 2005).

A análise dirigida é indicada quando já existe uma pesquisa primária em relação ao assunto proposto, objetivando legitimar ou amplificar um conceito teórico. Já a análise somatória busca compreender o uso contextual das palavras, envolvendo a identificação, a comparação e a quantificação de palavra-chave ou conteúdo para interpretar um contexto associado com o uso de palavra ou frase. A análise convencional, por sua vez, objetiva a codificação de categorias derivadas diretamente dos dados que emergem do próprio discurso do participante, sem impor teorias ou categorias preconcebidas, sendo esta a modalidade utilizada no estudo (Hsieh, \& Shannon, 2005). 
Os dados foram analisados seguindo os passos de codificação dos dados, categorização, integração das categorias e descrição, sendo validado por pares. A codificação ocorreu a partir de leituras exaustivas que possibilitaram a familiarização com palavras e frases destacadas dos discursos dos participantes. Foram destacados trechos que possibilitaram compreender o todo e identificar os códigos, preservando as palavras usadas pelo participante, para captar os pensamentos e conceitos-chave (Hsieh, \& Shannon, 2005).

$\mathrm{Na}$ categorização, agrupou-se os trechos previamente codificados em categorias e subcategorias, fazendo-se marcações e anotações pertinentes. Na fase de integração das categorias, buscou-se encontrar as relações e semelhanças entre as categorias, atentando-se para os significados recorrentes nos dados e as considerações a serem obtidas. Na fase de descrição dos dados, procedeu-se a integração e relação dos dados categorizados com as anotações realizadas durante a análise e demais materiais referentes à pesquisa (Hsieh, \& Shannon, 2005).

A pesquisa respeitou a Resolução 466/12 do Conselho Nacional de Saúde (Brasil, 2012), sendo aprovada pelo Comitê de Ética em Pesquisa da instituição sob o parecer de no 3.182.231 (CAAE: 07493019.7.0000.0071). Após serem informados sobre a pesquisa e concordarem em participar, os profissionais selecionados assinaram o Termo de Consentimento Livre e Esclarecido.

Os discursos revelaram que o primeiro contato do profissional com o projeto "Narizes de Plantão" ocorreu, na maioria das vezes, durante a graduação. A análise dessas vivências possibilitou elaborar seis categorias temáticas, apresentadas a seguir. Os relatos dos participantes foram identificados com letra $\mathrm{C}$ (conversa) e o número correspondente à entrevista, como forma de garantir o sigilo das identidades dos profissionais.

\section{Resultados}

\subsection{Sentindo-se Motivado para Participar do Projeto}

Nesta categoria, evidenciam-se os fatores que motivaram o profissional a participar do projeto "Narizes de Plantão", passando a tomar conhecimento deste tipo de atividade por meio de outros alunos que eram membros do projeto.

[...] eu sabia só o que eles me contavam [os amigos que já participavam do projeto] [...]. Eles pareciam outra pessoa [após participar do projeto]. E aí, eu falei: "ah, eu acho que eu vou tentar fazer isso ai" [participar do projeto]. C5.

Conhecer previamente o coordenador do projeto "Narizes de plantão", que também era docente na instituição, foi outro fator que motivou o profissional a participar do projeto. Sua atuação era percebida como diferenciada na condução das aulas em relação aos demais docentes.
[...] E, assim, a gente sentia que ele era uma pessoa diferente... um professor diferente dos outros. Todos os outros eram "ok"... eram bons também. E ele também era bom, mas era diferente [...] Ele sempre foi um professor que tinha uma didática diferente dos outros, sabe? [...] C17.

Outro fator que motivou a participação no projeto foi a curiosidade em saber como era a experiência de ser palhaço. Participar de uma oficina experimental como o primeiro contato com o projeto também parece ter contribuído para que o profissional decidisse continuar em algumas situações.

\section{[...]eu tinha muita curiosidade também, de como... o que era usar a máscara do palhaço dentro de um hospital. Eu tinha muita essa curiosidade [...]. C9}

Então, nós tivemos uma oficina experimental e, a partir daquela oficina, o pessoal que quis participar, participou. Foi assim que aconteceu. Eu gostei da oficina, da proposta e foi assim... Falei sim. C4. 


\subsection{Sendo Difícil Entender em que Consistia o Projeto Antes de Participar dele}

Para o profissional interessado em participar do projeto, era difícil entender do que se tratava apenas pelas informações fornecidas pelos colegas que já faziam parte dele. Segundo ele, só é possível compreender o que acontece durante essas atividades, quando passa a participar delas.

[...] olhando hoje, eu falo: "Caraca, eu não tinha noção de nada". Porque acho que só participando, a gente sabe o que você vivencia ali... o que você aprende e o quanto você cresce, né? C6.

\subsection{Temendo a Exposição ao Participar do Projeto}

O profissional que tinha um perfil mais introvertido surpreendia-se ao se interessar pelo projeto, reconhecendo como um desafio o fato de ter que se expor ao assumir o papel de palhaço.

Sempre fiquei curioso [em relação ao projeto], mas meio receoso, porque eu sou um cara um pouco mais tímido em algumas situações...outras vezes, sou bem extrovertido. Então, eu não sabia como lidar, né? Como que é ser palhaço... assim, se expor e estar tão exposto para todo mundo... para tudo. Fiquei bem receoso. C2.

\subsection{Entendendo o Palhaço como uma Possibilidade de Ser, Independentemente do seu Perfil Pessoal}

Após superada a barreira em relação ao receio de se expor, o profissional passa a reconhecer a figura do palhaço como uma possibilidade de ser independentemente do seu perfil pessoal, mais ou menos extrovertido. Essa experiência parece ter favorecido o autoconhecimento e o desenvolvimento da autoconfiança.

[...] eu nunca fui o palhaço engraçado... Eu tinha as minhas limitações, eu era muito mais o "Branco" [figura de palhaço mais sério] [...] C7.

[...] e tem lugar para todos, né? Isso que eu gostei. Você não tem que ter o perfil " $x$ ", sei lá...do Didi Mocó, para ser considerado um palhaço. Você não tem que ser o Chaves. Você não tem que ser, sei lá, o Mister Bean. Você pode ser você e daí [...] C8.

\subsection{Descobrindo uma Maneira Diferente de Atuar como Profissional}

Tornar-se palhaço permitiu ao entrevistado vislumbrar, enquanto estudante, possibilidades de atuação no futuro que vão muito além do que ele esperava para a profissão, com ênfase para uma abordagem mais humana na assistência ao paciente. Constituiu-se em uma oportunidade genuína de se perceber como profissional, segundo sua perspectiva de vida, a partir desta nova vivência que o projeto Ihe propiciou.

E eu sempre achei que tinha mais por trás do cuidado com o paciente que só saber a parte técnica. E nos primeiros dois anos da faculdade, eu lutei muito para não sair [do curso]. Porque eu ficava assim: "gente, não é o que eu quero fazer... Não dá". E aí, surgiu o palhaço. [...] Existe campo para pessoas que pensam de maneira diferente e aí, eu comecei a me identificar um pouco mais e me achei assim: "ah, eu posso ser eu e ser médico". E aí, foi quando eu vi que dava para fazer medicina de outra maneira, sabe? C8. 


\subsection{Sendo o Projeto uma Válvula de Escape para Aliviar o Estresse Vivido na Graduação}

O projeto também representou um momento de alívio e relaxamento para o entrevistado enquanto graduando, frente às demandas acadêmicas do curso e seus inúmeros desafios.

Quando eu estava nos "Narizes de Plantão", eu acho que era nossa fuga... de todo mundo que participava, né? [...] Podia ser um dia super cansativo, mas aí, no fim do dia, a gente falava assim: "Puts, hoje tem oficina... hoje é um dia que a gente consegue se soltar e relaxar, curtir e aproveitar" C11.

E apesar de todas as atividades acadêmicas a serem cumpridas no curso de graduação, o profissional que fazia parte do projeto enquanto aluno, empenhava-se em continuar a participar, mesmo diante das dificuldades enfrentadas, por ser algo prazeroso.

[...] não me arrependo um segundo. Eu ia virado de plantão para as oficinas [de palhaço] ... Melhor coisa do mundo. C2.

[...] apesar do sofrimento... que tinha uma questão muito de... além de eu trabalhar e fazer os estágios obrigatórios da faculdade, então eu tinha um turno duplo. E ainda tinham as oficinas, né? Às vezes, eu ia duas vezes no Ipiranga [unidade onde aconteciam as oficinas de palhaço] no mesmo dia... Eu moro em Taboão da Serra... dá uma hora e meia. C7.

\section{Discussão}

Os resultados revelaram que, para o profissional de saúde, ter participado do projeto "Narizes de Plantão" durante a graduação propiciou-Ihe um olhar diferenciado sobre a humanização do cuidado e o desenvolvimento de habilidades socioemocionais importantes para o exercício da profissão.

Um estudo realizado acerca da atuação dos "palhaços hospitalares" evidenciou, dentre os inumeros benefícios advindos desta vivência, o enriquecimento da relação estabelecida entre profissionais e estudantes com os pacientes (Sato, Ramos, Silva, \& Gameiro, 2016).

Quando adentra no ambiente hospitalar, o palhaço busca estabelecer uma ligação com os pacientes, familiares e profissionais de saúde capaz de criar uma relação de confiança mútua, possibilitando a todos os envolvidos desenvolver suas potencialidades por meio das artes cênicas. A partir da lógica do palhaço profissional, em consonância com as situações do contexto hospitalar, delineiam-se cenas teatrais em tempos e espaços reais (Brum, \& Porpino, 2017).

No presente estudo, um dos fatores que motivou o profissional a participar do projeto foram as conversas com pessoas que já faziam parte desta iniciativa. Esses achados corroboram com os resultados de dois estudos, realizados com acadêmicos e egressos do curso de medicina da Universidade Federal de Goiás, que cursaram uma disciplina abordando esta temática. A influência destes alunos atuou como força motivadora para o envolvimento de outras pessoas da comunidade acadêmica (Oliveira, 2014; Paiva, 2013).

No caso do projeto "Narizes de Plantão", apesar das conversas com alunos que já participavam do projeto, isso parecia não ser suficiente para que novos interessados entendessem de fato o que realmente acontecia nas oficinas de palhaços. Ocorre que o processo de formação do palhaço é puramente prático e vivencial, tornando-se difícil descrevê-lo para pessoas que ainda não o experienciaram (Masetti, 1998).

Na perspectiva do participante do presente estudo, o contato com a arte do palhaço na graduação permitiu-lhe vislumbrar uma maneira diferente de exercer a profissão, constituindo-se em uma oportunidade genuína de se perceber como profissional, a partir da vivência de autoconhecimento propiciada pelo projeto. 
Essa descoberta das novas possibilidades de atuação na profissão pelo graduando, sob a ótica do processo interpretativo proposto por Blumer, significa que o sujeito primeiramente exibe a si mesmo as coisas que têm sentido, num processo interno de comunicação e interpretação consigo mesmo. Após essa etapa de autoconhecimento, ele interpreta e atribui significados à essa interação, fazendo a seleção, a checagem, o reagrupamento e a transformação desses significados, vislumbrando uma nova concepção para atuar na vida profissional (Haguette, 2010).

De acordo com o IS, o significado que o profissional atribui à experiência de interagir com o seu próprio palhaço é construído a partir da interação que ele estabelece consigo mesmo, com os colegas de turma, pacientes, equipe multiprofissional e sociedade. E ao redefinir o self (ambiente interno da própria pessoa, segundo o IS) e assumir o papel do outro, o profissional-palhaço age e interage com diversas situações que passam a ser ressignificadas a medida em que avalia o momento presente, atribuindo, assim, um novo olhar para sua experiência.

A inserção da arte do palhaço no processo de humanização do profissional em formação, leva o acadêmico a reelaborar a própria maneira de avaliar a postura profissional em relação ao paciente, passando a percebê-lo além da sua doença (Oliveira, 2014).

Alunos que tiveram contato com a arte do palhaço durante a formação acadêmica demonstraram maior capacidade de enxergar o mundo pelos "olhos do outro", aceitando pontos de vista diferentes dos seus, levando a outra pessoa a se sentir compreendida e acolhida (Silva, Sampaio, \& Santos, 2019).

O desenvolvimento de habilidades não técnicas, como a capacidade de escuta, de contato visual, de lidar com falhas, de compreender o outro e de compartilhar momentos de dor e sofrimento é um ponto positivo resultante da participação dos estudantes de saúde em projetos universitários relacionados a vivências com palhaços hospitalares (Lanzieri, Claro, Bragança, Montezano, \& Silva, 2011; Nogueira-Martins, Lima-Costa, NogueiraMartins, \& Nogueira-Martins, 2014).

Além de proporcionar o desenvolvimento de competências profissionais que contribuem para tornar o atendimento mais humanizado, o projeto "Narizes de Plantão" também constituiu-se, para os participantes, em uma válvula de escape para enfrentar o estresse durante a graduação, representando um momento de alívio e relaxamento frente às demandas acadêmicas.

Em uma pesquisa realizada no Reino Unido com estudantes de medicina de um programa abrangendo conteúdos relacionados às artes, os estudantes encontraram um espaço para equilíbrio, reflexão e compreensão em meio às demandas de uma vida profissional intensa. Eles reconheceram, ainda, a contribuição dessa experiência no desenvolvimento de habilidades importantes para fortalecer a prática, levando-os a se comunicarem de maneira mais eficaz e a melhorarem a autoconfiança (Croix, Rose, Wildig, \& Willson, 2011).

Outro achado interessante do presente estudo é o fato do profissional enquanto graduando se sentir mais confiante após superar o medo da exposição ao participar das aulas de palhaço. Em um dos estudos anteriormente citado, alunos da Universidade Federal de Goiás que vivenciaram a arte do palhaço relataram sentir medo e ansiedade nas primeiras visitas dos acadêmicos como palhaços dentro do ambiente hospitalar e não durante as atividades teóricas desenvolvidas em sala de aulas sobre essa temática (Oliveira, 2014).

Esse processo desafiador de exposição e revelação do próprio palhaço também abre espaço para o acolhimento e a aceitação, possibilitando aos participantes do projeto "Narizes de Plantão" reconhecerem a figura do palhaço como algo a ser apropriado por qualquer pessoa, seja ela mais ou menos extrovertida. A literatura aponta que alunos mais tímidos que participaram de atividades sobre a arte do palhaço conseguiram superar sua timidez e, consequentemente, desenvolver habilidades de comunicação (Paiva, 2013). 
A compreensão da vivência da arte do palhaço para profissionais de saúde durante a graduação levou à reflexão sobre a importância de se implementar estratégias educativas que promovam o autoconhecimento do aluno, sensibilizando-o para as questões relacionadas à humanização do cuidado.

\section{Conclusões}

Este estudo possibilitou compreender o significado da vivência do profissional de saúde com a arte do palhaço a participar de um um projeto de extensão durante a graduação. Esta estratégia educacional mostrou-se efetiva no desenvolvimento e o aprimoramento de habilidades socioemocionais em estudantes do ensino superior na área da saúde.

Além disso, a experiência no projeto em questão contribuiu para o alívio do estresse durante o período acadêmico, possibilitando ao aluno ampliar as perspectivas futuras para a profissão, vislumbrando uma nova forma de atuação na prática. Enquanto estudante, o profissional revelou encontrar mais sentido no ato de cuidar, indo além do tecnicismo, e passando a valorizar a escutar e o olhar na interação com o paciente.

Este estudo traz subsídios que poderão contribuir para o aperfeiçoamento do conhecimento científico acerca do uso da linguagem do palhaço enquanto tecnologia facilitadora das práticas educacionais e de cuidados em saúde.

A investigação qualitativa revelou-se como uma estratégia exitosa de investigação das questões interacionais entre as pessoas envolvidas no contexto de pesquisa, possibilitando aos pesquisadores aprofundar sua compreensão sobre a influência da arte do palhaço no processo de formação do profissional de saúde.

\section{Referências}

Blumer, H. (1969). The methodological position of symbolic interactionism. In: H. Blumer. Symbolic interacionism: perspective e method. (pp.1-60). University of California.

Brasil. Ministério da Saúde. (2012). Conselho Nacional de Saúde. Resolução n. 466, de 12 de dezembro de 2012. Aprova diretrizes e normas regulamentadoras de pesquisas envolvendo seres humanos. Diário Oficial da União, Brasília (DF), Seção 1:59.

Brum, D.C.,\& Porpino, K.O. (2017). Figuras palhacescas: um percurso até os palcos hospitalares. Concept, 6(1)106-23.

Cardozo, E.E., \& Munari, D.B. (2005). A formação integral dos profissionais de saúde: possibilidades para a humanização da assistência. Ciênc Cuid Saúde,4(2):163 -70.

Charon, J.M. (2004). Symbolic interactionism: an introduction, an interpretation, an integration. New Jersey: Prentice Hall.

Croix, A., Rose, C., Wildig, E., \& Willson, S. (2011). Arts-based learning in medical education: the students' perspective. Med Educ,45(11):1090-100.

Doutores da Alegria. (2020). Conheça. https://doutoresdaalegria.org.br/

Haguette, T.M. (2010). Metodologias qualitativas na sociologia. (12a ed.).Vozes.

Hsieh, H.F., \& Shannon, S.E.(2005). Three approaches to qualitative content analysis. Qual Health Res, 2005;15(9):1277-88.

Lanzieri, P.G., Claro, L.B., Bragança, F.C., Montezano, V.R., \& Silva CS. (2011). "Boa noite, bom dia HUAP!", uma experiência de humanização na formação de profissionais da área de saúde. Interface Comun Saúde Educ,15(36):289-98.

Masetti, M. (1998). Soluções de palhaços: transformações na realidade hospitalar. Palas Athena.

Narizes de Plantão. (2019). Muito prazer! http://narizesdeplantao.com.br/ 
Nogueira-Martins, M.F., Lima-Costa, D., Nogueira-Martins, L.A., \& Nogueira-Martins, MC. (2014). Perceptions of healthcare undergraduate students about a hospital clown training. Creat Educ, 5(8):542-51.

Nunes, E.C., Silva, L.W.,\& Pires, E.P. (2011). O ensino superior de enfermagem: implicações da formação profissional para o cuidado transpessoal. Rev Lat Am Enfermagem,19(2):252-60.

Oliveira, A.S. (2014). Palhaço no hospital: percepção da influência do pronto sorriso como instrumento de aprendizagem no ensino da graduação em medicina. [Tese de doutorado, Universidade Federal de Goiás]. 106 p.

Paiva, M.L.(2013). Contribuições do Pronto Sorriso na formação do profissional de saúde. [Tese de doutorado, Universidade Federal de Goiás], $67 \mathrm{f}$

Ribeiro, C.A,\& Pettengill, M.A. (2006). A abordagem interacionista. In: Matheus MC \& Fustinoni SM (Coord.) Pesquisa qualitativa em enfermagem. (pp. 35-4). Livraria Médica Paulista.

Rolim, K.M, Campos, A.C, Cardoso, M.V., \& Silva, R.M. (2004). Sensibilizando os discentes para o cuidado humanizado: vivências do ensino-aprendizagem. Rev RENE, 5(2):79-85

Sato, M., Ramos, A., Silva, C.C., Gameiro, G.R, \& Scatena, C.M. (2016). Palhaços: uma revisão acerca do uso dessa máscara no ambiente hospitalar. Interface Comun Saúde Educ,20(56):123-34.

Silva, M, Sampaio J, \&, Santos E. (2019). O nível de empatia de participantes do projeto de extensão universitária sorriso de plantão e sua contribuição para a formação em saúde. Rev Contexto Saúde.19(36):79-90 